\title{
A COMPARATIVE STUDY OF 0.25\% BUPIVACAINE AND 0.25\% ROPIVACAINE FOR PAEDIATRIC CAUDAL BLOCK FOR INFRAUMBILICAL SURGERIES
}

\author{
A. Suresh ${ }^{1}$, N. Basker², S. Balasubramaniam³ \\ ${ }^{1}$ Assistant Professor, Department of Anaesthesiology, Chengalpattu Medical College. \\ ${ }^{2}$ Associate Professor, Department of Anaesthesiology, Chengalpattu Medical College. \\ 3Professor, Department of Anaesthesiology, Chengalpattu Medical College.
}

\begin{abstract}
BACKGROUND

Regional anaesthesia plays an enormous role in providing pain relief both in the intra-operative and post-operative periods in paediatrics. Caudal epidural anaesthesia is the most commonly performed regional anaesthetic technique in children. The availability of newer drugs with reduced toxic potentials led us to conduct a study in which we compared the duration of postoperative analgesia between the drugs for infraumbilical surgeries.

To compare Bupivacaine and Ropivacaine in a concentration of $0.25 \%$, given in a volume of $1 \mathrm{~mL} / \mathrm{kg}$ through a single Presurgical Caudal block in children aged 2-8 years undergoing surgeries like herniotomy and circumcision in terms of duration of postoperative analgesia.
\end{abstract}

\section{MATERIALS AND METHODS}

The present study was carried out in the Department of Anaesthesiology, Govt. Chengalpattu Medical College, Chengalpattu, in 60 patients of either sex of ASA Grade I, between the ages of 2 and 8 years. These patients were systematically randomised into groups of 30 each, Group A received $1 \mathrm{~mL} / \mathrm{kg}$ of $0.25 \%$ Bupivacaine $(0.5 \%$ solution diluted in equal volumes of normal saline) and Group B received $1 \mathrm{~mL} / \mathrm{kg}$ of $0.25 \%$ Ropivacaine $(0.5 \%$ solution diluted in equal volumes of Normal Saline) through the caudal route.

Statistical Analysis - The data was analysed by statistical software SPSS 17.0 and XLSTAT 2013. Independent student ' $t$ ' test was used to find the significance in continuous data between the two groups. Chi-square test was used to analyse categorical data.

\section{RESULTS}

The two groups were comparable in their baseline characteristics like age, sex, weight, height, vital signs, duration and type of surgery. The duration of postoperative pain relief between the groups were $182.83 \pm 12.64$ mins. in Group A and $110.17 \pm 8.66$ in Group B with a $\mathrm{P}<0.001$. The time to full motor recovery was significantly less in Ropivacaine group than in bupivacaine group. In Group A $239.00 \pm 21.55$ mins. and in Group B $162.00 \pm 20.24$ mins. with a $\mathrm{P}<0.001$.

\section{CONCLUSION}

Caudal Bupivacaine $0.25 \%$ in a dose of $1 \mathrm{~mL} / \mathrm{kg}$ provided reliable and long lasting analgesia when compared to Ropivacaine $0.25 \%$ in children undergoing infraumbilical surgeries.

\section{KEYWORDS}

Caudal Block, Ropivacaine, Bupivacaine, Postoperative Analgesia.

HOW TO CITE THIS ARTICLE: Suresh A, Basker N, Balasubramaniam S. A comparative study of $0.25 \%$ bupivacaine and $0.25 \%$ ropivacaine for paediatric caudal block for infraumbilical surgeries. J. Evolution Med. Dent. Sci. 2016;5(86):6403-6408, DOI: $10.14260 /$ jemds/2016/1448

\section{BACKGROUND}

Pain is an uncomfortable sensation or feeling, which has its influences on health. Everyone can feel pain; even infants and young children can perceive pain which can slow down the child's recovery. An additional quote that describes the pain experienced by children is, "The inability to communicate verbally does not negate the possibility that an individual is experiencing pain and is in need of appropriate pain-relieving treatment. Pain is always subjective." 1

Financial or Other, Competing Interest: None.

Submission 20-09-2016, Peer Review 14-10-2016,

Acceptance 20-10-2016, Published 27-10-2016.

Corresponding Author:

Dr. A. Suresh,

\#1/38, Alagesan Street,

Vedachalam Nagar, Chengalpattu,

Tamilnadu-603001.

E-mail: suresh_medic@yahoo.co.in

DOI: $10.14260 /$ jemds/2016/1448

\section{(c) (i) $\ominus$}

Regional anaesthesia plays an enormous role in providing pain relief both in the intra-operative and post-operative periods in paediatric day care procedures. The role of performing a caudal block prior to incision after general anaesthesia reduces the need of sedative opioids for pain relief and decreases the need of volatile anaesthetics for maintenance of anaesthesia intraoperatively. ${ }^{2}$ Regional anaesthesia through caudal route has its own disadvantage such as the residual motor block, which may be of distress to children in the postoperative period. ${ }^{3}$ Local anaesthetics are either used alone or with additives through the caudal route. Commonly used drugs are lignocaine, bupivacaine and ropivacaine. No drug can be considered ideal, because each drug has its own advantages and disadvantages.

Bupivacaine is a long-acting amide group of local anaesthetic that has provided both anaesthesia as well as analgesia with differential motor-sensory blockade. Most of the drug related toxicity occurs due to the technique rather than the drug by itself. Toxicity may occur due to accidental 
intravascular or intrathecal injection of bupivacaine resulting in severe neurological, cardiovascular depression even leading to death. Hence, studies were conducted on the mechanism of the cardiotoxic side effects of local anaesthetics and research for drugs with less cardiotoxic profile is continuing. 4,5 Bupivacaine is commercially available as racemic mixture of $\mathrm{R}$ and S-enantiomers. It acts by blocking sodium and potassium channels. This blockade of channels in the inactivated state is stereo-selective with R-bupivacaine more potent than Sbupivacaine. ${ }^{6}$

In response to increased cardiac toxicity associated with racemic mixtures of bupivacaine, single enantiomers were developed and Ropivacaine is the first local anaesthetic agent to be manufactured as a pure S-enantiomer. ${ }^{7}$ Studies have shown that ropivacaine is less cardiotoxic and neurotoxic than bupivacaine. The sensory block produced by it is similar to that produced by bupivacaine in epidural and peripheral nerve blocks. The motor block produced by ropivacaine has a slower onset of action, which is less intense and has a shorter duration of action than bupivacaine. It has a less cardiotoxic and less neurotoxic profile than the racemic bupivacaine. 8,9

\section{MATERIALS AND METHODS}

This was a Prospective, Double blinded, Randomised Comparative Study conducted in Government Chengalpattu Medical College and Hospital, Chengalpattu. After obtaining clearance from the Institutional Ethical Committee, Written Informed Consent from each parent was obtained in their vernacular language and the study was explained in detail to them.

A Pilot study was first conducted to define the population and to decide on the inclusion and exclusion criteria, and the target population of 30 subjects in each group was decided. Sixty children who were admitted to the Paediatric Surgery Department for elective surgeries were selected for the study. The sixty children satisfying the selection criteria were randomised by computer generated randomisation table into two groups of thirty each - Group A and Group B. The randomisation sequence was prepared in double-blinded manner. The study blinding was broken after the statistical analysis.

The children in Group A received $1 \mathrm{~mL} / \mathrm{kg}$ of $0.25 \%$ Bupivacaine $(0.5 \%$ solution diluted in equal volumes of normal saline), whereas those in Group B received $1 \mathrm{~mL} / \mathrm{kg}$ of $0.25 \%$ Ropivacaine $(0.5 \%$ solution diluted in equal volumes of normal saline) through the caudal route.

\section{Criteria for Patient Selection}

Children aged 2-8 years of either sex belonging to ASA I physical status, undergoing elective lower abdominal or urologic surgeries like Herniotomy, Processus vaginalis sac ligation, Circumcision and Hypospadias were included in the study.

\section{Exclusion Criteria}

The Children with the following Problems were Excluded from the Study

- Local infection in the Caudal region.

- Pre-existing Neuromuscular disease.

- Congenital anomaly of the lower back.

- Mental retardation.

- Delayed development.

- Bleeding diathesis.

\section{Study Methods}

All consented patients classified under American Society of Anaesthesiologist's physical status I were selected. They were randomly allocated using computer generated randomisation table into two groups, Group A and B.

The randomisation sequence was prepared in a doubleblinded manner. The study solution was prepared by a final year post-graduate student who was not associated with the study. The caudal block was performed by an assistant professor who was also blinded to the study. The observations were done by the author. The study blinding was broken after the statistical analysis.

The details of the study were explained to the parents in their vernacular language and informed consent was obtained on the day prior to surgery. Patients were transferred to the premedication room along with the parents, baseline parameters recorded, oral midazolam $(0.4 \mathrm{mg} / \mathrm{kg})$ was given 40 mins. before the procedure. ${ }^{10}$

Patients were wheeled into the operation theatre, Standard Monitors like Pulse Oximeter, Blood pressure, ECG were connected and after recording Baseline parameters IV line accessed via $22 \mathrm{G}$ or $24 \mathrm{G}$ IV cannula, Ringer lactate maintenance fluid started, 11 the child was preoxygenated with $100 \% \mathrm{O}_{2}$ for 3 minutes and induced with Inj. fentanyl $2 \mathrm{mic} / \mathrm{kg}$ IV and Inj. Propofol $2.5 \mathrm{mg} / \mathrm{kg}$ IV and anaesthesia was maintained with spontaneous ventilation via face mask with $\mathrm{N}_{2} \mathrm{O}: \mathrm{O}_{2}$ (2:2) connected via Modified Jackson Rees circuit and with infusion of Inj. propofol $15 \mathrm{mg} / \mathrm{kg} / \mathrm{hr}$ for the first 15 mins., $13 \mathrm{mg} / \mathrm{kg} / \mathrm{hr}$ for the next $15 \mathrm{mins}$., $11 \mathrm{mg} / \mathrm{kg} / \mathrm{hr}$ from 30-60 mins. IV.12,13

The child was placed in left lateral position and under full aseptic precautions, a sterile $22 \mathrm{G}$ hypodermic needle was introduced in the caudal epidural space and after confirming the space, $1 \mathrm{~mL} / \mathrm{kg}$ of $0.25 \%$ bupivacaine or $0.25 \%$ ropivacaine was administered in slow increments. The patients were placed in supine position and anaesthesia continued with facemask with Nitrous Oxide and Oxygen mixture (2:2) with Inj. propofol $15 \mathrm{mg} / \mathrm{kg} / \mathrm{hr}$ for the first 15 mins., $13 \mathrm{mg} / \mathrm{kg} / \mathrm{hr}$ for the next 15 mins., $11 \mathrm{mg} / \mathrm{kg} / \mathrm{hr}$ from 30-60 mins. IV. The incision was made 10 mins. after caudal block.

The observer recorded the heart rate and blood pressure, oxygen saturation just before and after $(0 \mathrm{~min}, 3$ mins., 5 mins.) surgical incision and then every 5 mins. interval till the end of surgery. If the patient responded to the incision with a greater than 20\% increase in Systolic Blood Pressure or Heart Rate, Inj. Fentanyl $1 \mu \mathrm{g} / \mathrm{kg}$ IV was administered and the child was excluded from the study. Propofol infusion was discontinued at the end of the procedure. After completion of the surgical procedure, the children were shifted to the recovery room for continuous observation.

Post-Operatively, apart from Monitoring Pulse Rate, Systolic Blood Pressure and Oxygen Saturation, the following Parameters were Assessed

A. Quality of post-operative Analgesia was assessed by Modified Hannallah Objective Pain Scale (Table 1) every 15 mins. for the first two hours and every 30 mins. for the next 5 hours.

B. The time between the caudal block and administration of the first rescue analgesic drug was noted. Inj. fentanyl 1 $\mathrm{mic} / \mathrm{kg}$ will be given as rescue analgesic when the pain score equals 4. 
C. To assess the degree of motor blockade by motor power scale (Table 2) every 15 mins. for the first two hours and every 30 mins. for the next 5 hours.

D. Adverse events or complications were noted.

\section{Statistical Methods}

The data was analysed by statistical software SPSS 17.0 and XLSTAT 2013. Independent student ' $t$ ' test was used to find the significance in continuous data between the two groups. Chisquare test was used to analyse categorical data. The $p$ value of less than 0.05 was considered as statistically significant.

\section{RESULTS}

The two groups were comparable with respect to the age, height, weight and sex (Table 3). There was no statistical difference between the two groups in the demographic profile. The two groups were comparable in terms of ASA physical status, type of surgery (Table 4) and duration of surgery (Table 7). There is no statistically significant difference between the groups. There is no statistically significant difference between the groups in terms of Mean Heart Rate (Table 5), MAP (Table 6) during the surgical procedure.

There is statistically significant difference between the drugs in the full motor recovery $(p=0.000)$ (Table 8). The time to full motor recovery was significantly less in ropivacaine group than bupivacaine group. In Group A $(239.00 \pm 21.55$ mins.) and in Group B (162.00 \pm 20.24 mins.) with a $\mathrm{P}<0.001$.

There is statistically significant difference between the drugs at the time of first analgesia (Table 8). The quality and duration of postoperative pain relief between the groups are in Group A it is $182.83 \pm 12.64$ mins. and in Group B $110.17 \pm 8.66$ mins. with a $\mathrm{P}<0.001$.

There is statistically significant difference among the groups in the mean pain score (Table 9) readings taken in all times except 30 mins. and after 180 mins. $(p<0.05)$.

There is statistically significant difference among the groups in the Mean Motor Power Scale (Table 10) readings taken in all times except 15 mins. and after 240 mins. ( $p<$ 0.05).

There is no statistically significant difference between the groups in the postoperative pulse rate, SPO2 and SBP.

\begin{tabular}{|c|c|c|c|}
\hline $\begin{array}{c}\text { Sl. } \\
\text { No. }\end{array}$ & Observation & Criteria & Points \\
\hline 1 & Crying & No Crying & 0 \\
\hline & & $\begin{array}{c}\text { Crying, Responding to } \\
\text { tender Loving Care }\end{array}$ & 1 \\
\hline & $\begin{array}{c}\text { Crying, not } \\
\text { Responding to TLC }\end{array}$ & 2 \\
\hline 2 & Movement & None & 0 \\
\hline & & Restless & 1 \\
\hline 3 & Agitation & Asleep/Calm & 2 \\
\hline & & Mild & 1 \\
\hline & & Hysterical & 2 \\
\hline 4 & $\begin{array}{c}\text { Swallowing of } \\
\text { Secretions }\end{array}$ & Normal & 0 \\
\hline & & Uncomfortable & 1 \\
\hline & & Unable & 2 \\
\hline 5 & $\begin{array}{c}\text { Verbalisation } \\
\text { of Pain }\end{array}$ & $\begin{array}{c}\text { Asleep/States } \\
\text { No Pain }\end{array}$ & 0 \\
\hline & & Vague/Cannot Localise & 1 \\
\hline & & Can Localise Pain & 2 \\
\hline & Table 1. Modified Hannallah Pain Scale \\
\hline
\end{tabular}

\begin{tabular}{|c|c|c|c|}
\hline Muscle Tone & Flaccid & Hypotonia & Normal \\
\hline & 0 & 1 & 2 \\
\hline $\begin{array}{l}\text { Muscle Power } \\
\text { (Flexion) }\end{array}$ & Unable & Partial & Normal \\
\hline Ankle & 0 & 1 & 2 \\
\hline Knee & 0 & 1 & 2 \\
\hline Thigh & 0 & 1 & 2 \\
\hline Ability to Stand & 0 & 1 & 2 \\
\hline \multicolumn{4}{|c|}{ Table 2. Motor Power Scale } \\
\hline
\end{tabular}

\begin{tabular}{|c|c|c|c|}
\hline $\begin{array}{c}\text { Patient } \\
\text { Characteristics }\end{array}$ & $\begin{array}{c}\text { Bupivacaine } \\
\mathbf{0 . 2 5 \%}\end{array}$ & $\begin{array}{c}\text { Ropivacaine } \\
\mathbf{0 . 2 5 \%}\end{array}$ & $\begin{array}{c}\mathbf{p} \\
\text { value }\end{array}$ \\
\hline Age (Years) & $4.12 \pm 1.86$ & $4.68 \pm 1.87$ & 0.2496 \\
\hline $\begin{array}{c}\text { Sex } \\
\text { (Male/Female) }\end{array}$ & $26 / 4$ & $23 / 7$ & 0.3191 \\
\hline Weight* $^{*}$ & $13.53 \pm 2.83$ & $14.03 \pm 2.99$ & 0.5086 \\
\hline Height* & $108.93 \pm 5.82$ & $110.50 \pm 7.46$ & 0.3672 \\
\hline \multicolumn{4}{|r|}{ Table 3. Patient's Characteristics } \\
\hline
\end{tabular}

*Values are expressed as Mean \pm SD

\begin{tabular}{|c|c|c|c|}
\hline Surgery & $\begin{array}{c}\text { Bupivacaine } \\
\mathbf{0 . 2 5 \%}\end{array}$ & $\begin{array}{c}\text { Ropivacaine } \\
\mathbf{0 . 2 5 \%}\end{array}$ & Total \\
\hline Circumcision & $19(63 \%)$ & $14(47 \%)$ & $49(55 \%)$ \\
\hline Hypospadias & 0 & $1(3 \%)$ & $2(2 \%)$ \\
\hline LIH & $2(7 \%)$ & $6(20 \%)$ & $11(12 \%)$ \\
\hline LPVSL & $2(7 \%)$ & 0 & $3(3 \%)$ \\
\hline RIH & $6(20 \%)$ & $5(17 \%)$ & $18(20 \%)$ \\
\hline RPVSL & $1(3 \%)$ & $4(13 \%)$ & $7(8 \%)$ \\
\hline Total & $\mathbf{3 0 ( 1 0 0 \% )}$ & $\mathbf{3 0}(\mathbf{1 0 0} \%)$ & $\mathbf{6 0}(\mathbf{1 0 0} \%)$ \\
\hline \multicolumn{4}{|c|}{ Table 4. Type of Surgery } \\
\hline
\end{tabular}

\begin{tabular}{|c|c|c|c|c|c|}
\hline & \multicolumn{2}{|c|}{ Bupivacaine 0.25\% } & \multicolumn{2}{c|}{$\begin{array}{c}\text { Ropivacaine } \\
\mathbf{0 . 2 5 \%}\end{array}$} & $\begin{array}{c}\mathbf{p} \\
\text { value }\end{array}$ \\
\hline & $\mathbf{N}$ & Mean \pm SD & $\mathbf{N}$ & Mean \pm SD & \\
\hline HR Base & 30 & $122.70 \pm 7.78$ & 30 & $121.90 \pm 7.68$ & 0.6900 \\
\hline 3 mins. & 30 & $115.73 \pm 8.23$ & 30 & $114.03 \pm 8.96$ & 0.4472 \\
\hline 5 mins. & 30 & $112.57 \pm 7.75$ & 30 & $108.80 \pm 20.43$ & 0.3486 \\
\hline 10 mins. & 30 & $111.70 \pm 7.83$ & 30 & $111.10 \pm 8.68$ & 0.7796 \\
\hline 15 mins. & 30 & $110.57 \pm 7.37$ & 30 & $109.80 \pm 7.97$ & 0.6991 \\
\hline 20 mins. & 29 & $111.07 \pm 7.90$ & 29 & $108.79 \pm 7.34$ & 0.2597 \\
\hline 25 mins. & 16 & $111.25 \pm 8.83$ & 18 & $108.83 \pm 7.50$ & 0.3989 \\
\hline 30 mins. & 11 & $113.91 \pm 9.22$ & 15 & $108.40 \pm 9.31$ & 0.1480 \\
\hline 35 mins. & 5 & $113.80 \pm 7.23$ & 11 & $111.09 \pm 9.43$ & 0.5432 \\
\hline 40 mins. & 2 & $112.50 \pm 2.12$ & 5 & $109.60 \pm 6.54$ & 0.4180 \\
\hline 45 mins. & 1 & 112.00 & 4 & $111.25 \pm 5.58$ & - \\
\hline 50 mins. & 0 & & 1 & 107.00 & - \\
\hline \multicolumn{5}{|c}{ Table 5. Mean Heart Rate (MHR) } \\
\hline
\end{tabular}

\begin{tabular}{|c|c|c|c|c|c|}
\hline & \multicolumn{2}{|c|}{$\begin{array}{c}\text { Bupivacaine } \\
\mathbf{0 . 2 5 \%}\end{array}$} & \multicolumn{2}{c|}{$\begin{array}{c}\text { Ropivacaine } \\
\mathbf{0 . 2 5 \%}\end{array}$} & $\begin{array}{c}\mathbf{p} \\
\text { value }\end{array}$ \\
\hline & $\mathbf{N}$ & Mean \pm SD & $\mathbf{N}$ & Mean \pm SD & \\
\hline $\begin{array}{c}\text { MAP } \\
\text { Base }\end{array}$ & 30 & $74.55 \pm 2.69$ & 30 & $74.95 \pm 2.48$ & 0.5516 \\
\hline 0 min & 30 & $72.33 \pm 2.21$ & 30 & $72.87 \pm 2.15$ & 0.3414 \\
\hline 3 mins. & 30 & $70.95 \pm 2.17$ & 30 & $71.64 \pm 1.93$ & 0.1983 \\
\hline 5 mins. & 30 & $70.62 \pm 1.45$ & 30 & $70.97 \pm 1.82$ & 0.4134 \\
\hline 10 mins. & 30 & $70.40 \pm 1.12$ & 30 & $70.82 \pm 1.31$ & 0.1872 \\
\hline 15 mins. & 29 & $71.12 \pm 1.14$ & 30 & $71.29 \pm 1.05$ & 0.5541 \\
\hline 20 mins. & 29 & $71.61 \pm 1.35$ & 28 & $72.31 \pm 1.46$ & 0.0658 \\
\hline 25 mins. & 15 & $71.91 \pm 1.18$ & 18 & $72.00 \pm 1.75$ & 0.8619 \\
\hline 30 mins. & 11 & $71.81 \pm 1.64$ & 15 & $71.55 \pm 1.50$ & 0.6831 \\
\hline 35 mins. & 5 & $72.79 \pm 0.87$ & 11 & $72.61 \pm 1.75$ & 0.7877 \\
\hline 40 mins. & 2 & $75.67 \pm 0.47$ & 4 & $75.16 \pm 0.84$ & 0.6478 \\
\hline 45 mins. & 1 & 75.33 & 3 & $74.89 \pm 0.77$ & - \\
\hline 50 mins. & 0 & \multicolumn{5}{|c|}{1} & 72.67 & - \\
\hline \multicolumn{5}{|c|}{ Table 6. Mean Arterial Pressure (MAP) } \\
\hline
\end{tabular}




\begin{tabular}{|c|c|c|c|}
\hline & $\begin{array}{c}\text { Bupivacaine } \\
\mathbf{0 . 2 5 \%}\end{array}$ & $\begin{array}{c}\text { Ropivacaine } \\
\mathbf{0 . 2 5 \%}\end{array}$ & $\begin{array}{c}\mathbf{p} \\
\text { value }\end{array}$ \\
\hline $\begin{array}{c}\text { Duration of } \\
\text { Surgery (mins.) }\end{array}$ & $25.67 \pm 7.16$ & $28.50 \pm 9.21$ & 0.1891 \\
\hline \multicolumn{3}{|c|}{$\begin{array}{c}\text { Table 7. Comparison of Duration of Surgery among } \\
\text { Bupivacaine 0.25\% and Ropivacaine 0.25\% }\end{array}$} \\
\hline
\end{tabular}

\begin{tabular}{|c|c|c|c|}
\hline & $\begin{array}{c}\text { Bupivacaine } \\
\mathbf{0 . 2 5 \%}\end{array}$ & $\begin{array}{c}\text { Ropivacaine } \\
\mathbf{0 . 2 5 \%}\end{array}$ & $\begin{array}{c}\mathbf{p} \\
\text { Value }\end{array}$ \\
\hline $\begin{array}{c}\text { Full Motor } \\
\text { Recovery (mins.) }\end{array}$ & $239.00 \pm 21.55$ & $162.00 \pm 20.24$ & 0.0001 \\
\hline $\begin{array}{c}\text { Time of First } \\
\text { Analgesia (mins.) }\end{array}$ & $182.83 \pm 12.64$ & $110.17 \pm 8.66$ & 0.0001 \\
\hline \multicolumn{3}{|c|}{ Table 8. Comparison of Full Motor Recovery and } \\
Time of First Analgesia among Bupivacaine \\
0.25\% and Ropivacaine 0.25\%
\end{tabular}

\begin{tabular}{|c|c|c|c|}
\hline $\begin{array}{c}\text { Pain } \\
\text { Score }\end{array}$ & $\begin{array}{c}\text { Bupivacaine } \\
\mathbf{0 . 2 5 \%} \\
(\mathbf{N}=\mathbf{3 0})\end{array}$ & $\begin{array}{c}\text { Ropivacaine } \\
\mathbf{0 . 2 5 \%} \\
(\mathbf{N}=\mathbf{3 0})\end{array}$ & $\begin{array}{c}\mathbf{p} \\
\text { value }\end{array}$ \\
\hline 0 min & .00 & .00 & - \\
\hline 15 mins. & .00 & .00 & - \\
\hline 30 mins. & $0.47 \pm 0.51$ & $0.43 \pm 0.50$ & 0.7601 \\
\hline 45 mins. & $0.90 \pm 0.55$ & $1.20 \pm 0.61$ & 0.0501 \\
\hline 60 mins. & $1.47 \pm 0.51$ & $1.77 \pm 0.43$ & 0.0167 \\
\hline 75 mins. & $1.87 \pm 0.65$ & $2.30 \pm 0.54$ & 0.0071 \\
\hline 90 mins. & $2.10 \pm 0.48$ & $3.07 \pm 0.37$ & 0.0001 \\
\hline 105 mins. & $2.80 \pm 0.41$ & $3.47 \pm 0.57$ & 0.0001 \\
\hline 120 mins. & $2.93 \pm 0.25$ & $3.30 \pm 0.70$ & 0.0084 \\
\hline 150 mins. & $3.13 \pm 0.43$ & $3.67 \pm 0.48$ & 0.0001 \\
\hline 180 mins. & $3.77 \pm 0.43$ & $3.57 \pm 0.50$ & 0.1021 \\
\hline 210 mins. & $3.37 \pm 0.67$ & $3.20 \pm 0.41$ & 0.2407 \\
\hline 240 mins. & $3.13 \pm 0.35$ & $3.13 \pm 0.37$ & 0.9999 \\
\hline 270 mins. & $3.00 \pm 0.74$ & $3.30 \pm 0.47$ & 0.0659 \\
\hline 300 mins. & $3.10 \pm 0.31$ & $3.00 \pm 0.37$ & 0.2612 \\
\hline Table 9. Comparison of Mean Pain Score among \\
Bupivacaine 0.25\% and Ropivacaine 0.25\% \\
\hline \multicolumn{4}{|c|}{}
\end{tabular}

\begin{tabular}{|c|c|c|c|}
\hline $\begin{array}{c}\text { Motor Power } \\
\text { Scale }\end{array}$ & $\begin{array}{c}\text { Bupivacaine } \\
\mathbf{0 . 2 5 \%} \\
\mathbf{( N = 3 0 )}\end{array}$ & $\begin{array}{c}\text { Ropivacaine } \\
\mathbf{0 . 2 5 \%} \\
\mathbf{( N = 3 0 )}\end{array}$ & $\begin{array}{c}\mathbf{P} \\
\text { Value }\end{array}$ \\
\hline 0 min & .00 & .00 & - \\
\hline 15 mins. & $0.07 \pm 0.36$ & $0.02 \pm 0.21$ & 0.5137 \\
\hline 30 mins. & $0.17 \pm 0.38$ & $0.70 \pm 0.98$ & 0.0076 \\
\hline 45 mins. & $1.53 \pm 0.77$ & $2.15 \pm 0.80$ & 0.0033 \\
\hline 60 mins. & $2.67 \pm 0.71$ & $3.40 \pm 0.77$ & 0.0003 \\
\hline 75 mins. & $3.47 \pm 0.86$ & $4.23 \pm 1.19$ & 0.0062 \\
\hline 90 mins. & $4.33 \pm 0.78$ & $5.70 \pm 0.98$ & 0.0001 \\
\hline 105 mins. & $5.27 \pm 0.94$ & $7.20 \pm 0.76$ & 0.0001 \\
\hline 120 mins. & $6.27 \pm 0.83$ & $8.17 \pm 0.79$ & 0.0001 \\
\hline 150 mins. & $7.30 \pm 0.84$ & $9.53 \pm 0.73$ & 0.0001 \\
\hline 180 mins. & $8.13 \pm 0.63$ & $9.97 \pm 0.18$ & 0.0001 \\
\hline 210 mins. & $9.03 \pm 0.62$ & 10.00 & 0.0001 \\
\hline 240 mins. & $9.70 \pm 0.59$ & 10.00 & 0.0072 \\
\hline 270 mins. & 10.00 & 10.00 & - \\
\hline 300 mins. & 10.00 & 10.00 & - \\
\hline \multicolumn{4}{|c|}{ Table 10. Comparison of Mean Motor Scale } \\
\hline among Bupivacaine 0.25\% and Ropivacaine 0.25\% \\
\hline \multicolumn{4}{|c|}{}
\end{tabular}

\section{DISCUSSION}

The aim of providing adequate pain relief in paediatric day care surgery is of vital importance, as it takes care of not only the intraoperative period but also the post-operative analgesic requirements. Surgical pain has got long-term behavioural effects in children. Caudal anaesthesia plays a major role in providing good pain relief in infraumbilical surgeries. Various studies showed that the effect of analgesia might vary between patients which depend on the type of the surgery, patient's age, type and volume of the local anaesthetic agent.

Our study shows that a single pre-surgical caudal injection of bupivacaine after induction of anaesthesia provides good quality of analgesia both during intraoperative period and the postoperative period than ropivacaine in patients coming for infraumbilical surgeries.

\section{Post-Operative Analgesia}

Locatelli et $\mathrm{al}^{14}$ compared $0.25 \%$ bupivacaine, levobupivacaine, ropivacaine in a dose of $1 \mathrm{~mL} / \mathrm{kg}$ for orchidopexy and hernia repair. For phimosis $0.5 \mathrm{~mL} / \mathrm{kg}$ was used. They reported that bupivacaine had longer analgesic effect than other two drugs. In our study, we compared the drugs in the same concentration and as standardised procedure all patients received $1 \mathrm{~mL} / \mathrm{kg}$ of the test drug. The results from our study are comparable with views supported by Locatelli et al in terms of postoperative analgesia.

Kaya $\mathrm{Z}$ et al ${ }^{15}$ studied $0.25 \%$ of bupivacaine and levobupivacaine for subumbilical surgeries in a dose of 0.5 $\mathrm{mL} / \mathrm{kg}$; he found that bupivacaine produced significant analgesia when compared with levobupivacaine.

Pablo M Ingelmo et al ${ }^{16}$ also compared similar drugs who found that there was no significant difference between the study drugs in terms of analgesia, but the effectiveness of caudal block was more with bupivacaine and levobupivacaine than ropivacaine. Astuto et al ${ }^{17}$ also found no significant difference between $0.25 \%$ levobupivacaine and ropivacaine in terms of mean duration of onset of caudal block and time of first analgesic administration.

G. Ivani et al18,19 did two different studies comparing levobupivacaine and ropivacaine. In one study he compared $0.25 \%$ ropivacaine and $0.25 \%$ levobupivacaine and in the other he compared $0.20 \%$ ropivacaine and $0.20 \%$ levobupivacaine, where he found that there was no significant difference between the mean time of onset of the caudal block and time of first analgesic administration.

In contrary to our study, Manjushree et $a^{20}$ when comparing $0.25 \%$ bupivacaine and ropivacaine found that ropivacaine provided effective analgesia and less motor block than bupivacaine.

Dobereiner et $\mathrm{al}^{21}$ showed in his study that there was no difference seen with the use of high dose of local anaesthetic agents on the quality of postoperative analgesia.

G. Ivani et al showed that the mean onset time of caudal $0.2 \%$ ropivacaine was 9 mins. with that of 12 mins. for $0.25 \%$ bupivacaine. Since our aim was not to compare the onset times, we used a fixed time of 10 mins. after caudal block for incision for all the groups. In our study, this was found to be adequate for all the test drugs with no child requiring fentanyl supplementation.

\section{Residual Motor Block}

Different studies have shown that postoperative motor block intensity and duration varies. With regards to this, Locatelli et al $^{14}$ and Ivani et al ${ }^{18,19}$ in their investigations found that bupivacaine had longer duration of motor blockade when compared to levobupivacaine, but this effect was reduced in the subsequent hours of followup. 
Breschan et $\mathrm{al}^{22}$ in their investigations compared levobupivacaine, ropivacaine and bupivacaine and found that ropivacaine and levobupivacaine had lower motor block than that of bupivacaine in the first two hours, but this difference was lost after two hours.

Kaya $\mathrm{Z}$ et al ${ }^{15}$ had also reported similar results in his studies where they compared levobupivacaine and bupivacaine, bupivacaine caused more duration of motor blockade and there was no residual motor block in both the groups after 150 minutes.

Our study results were comparable to the above studies, where bupivacaine produced a longer duration of motor blockade than ropivacaine.

In contrary to the above studies, Frawley et $\mathrm{al}^{23}$ reported that there was no significant difference between groups in terms of motor block in their study where they compared 1 $\mathrm{mL} / \mathrm{kg}$ of bupivacaine $0.25 \%$ and levobupivacaine $0.25 \%$. After 150 mins., there was no residual motor blockade observed between the groups.

There are studies that showed that motor block is proportional to the dose of the local anaesthetic used.

Only one child in ropivacaine and two children in bupivacaine group had vomiting postoperatively that was treated with Inj. Ondansetron $0.01 \mathrm{mg} / \mathrm{kg}$ IV. This may be due to the effects of general anaesthetics.

\section{Summary}

Bupivacaine is the most frequently used local anaesthetic for caudal anaesthesia in children that provides reliable and longlasting anaesthesia and analgesia. Ropivacaine is a newer local anaesthetic agent, which provides pain relief lesser than that of bupivacaine with less motor blockade.

The groups were comparable for age, sex, weight, height, vital signs, duration and type of surgery. The quality and duration of postoperative pain relief between the groups were $182.83 \pm 12.64$ mins. in Group A and $110.17 \pm 8.66$ mins. in Group B with a $\mathrm{P}<0.001$. The time to full motor recovery was significantly less in ropivacaine group than in bupivacaine group. In Group A it was $239.00 \pm 21.55$ mins. and in Group B $162.00 \pm 20.24$ mins. with a $P<0.001$. Postoperative vitals were stable in all the children. Apart from minor adverse events such as nausea and vomiting, no major adverse events were observed.

\section{CONCLUSION}

We conclude that in our randomised, prospective, double blinded study comparing Caudal Bupivacaine $0.25 \%$ and Ropivacaine $0.25 \%$ for post-operative analgesia, Caudal Bupivacaine $0.25 \%$ in a dose of $1 \mathrm{~mL} / \mathrm{kg}$ provided reliable and long lasting analgesia when compared to Ropivacaine $0.25 \%$ in children undergoing infraumbilical surgeries.

\section{ACKNOWLEDGEMENT}

We are very grateful to the Professors and Assistant Professors of the Department of Paediatric Surgery. We are extremely thankful to the Assistant Professors and the Postgraduates of the Department of Anaesthesiology for their help in carrying out this study. We are thankful to the Institutional Ethical Committee for their guidance and approval for this study. Last but not the least, we thank all our patients for willingly submitting themselves for this study. We also wish to state that no financial or material support was obtained for this study.

\section{REFERENCES}

1. Merskey H, Bogduk N. Part III: pain terms, a current list with definitions and notes on usage. Classification of chronic pain. $2^{\text {nd }}$ edn. Seattle: IASP Task Force on Taxonomy IASP Press 1994:209-14.

2. Dalens B, Hasnaoui A. Caudal anaesthesia in pediatric surgery: success rates and adverse effects in 750 consecutive patients. Anesth Analg 1989;68(2):83-9.

3. Murat I, Delleur MM, Esteve C, et al. Continuous extradural anaesthesia in children: clinical and haemodynamic implications. Br J Anaesth 1987;59(11):1441-50.

4. Albright GA. Cardiac arrest following regional anesthesia with etidocaine or bupivacaine. Anesthesiology 1979;51(4):285-7.

5. Marx GF. Cardiotoxicity of local anesthetics-the plot thickens. Anesthesiology 1984;60(1):3-5.

6. Valenzuela C, Delpon E, Tamkun MM, et al. Stereoselective block of a human cardiac potassium channel (Kv1.5) by bupivacaine enantiomers. Biophys J 1995;69(2):418-27.

7. McClure J. Ropivacaine. Br J Anaesth 1996;76(2): 300-7.

8. Knudsen K, Beckman SM, Blomberg S, et al. Central nervous and cardiovascular effects of i.v. infusions of ropivacaine, bupivacaine and placebo in volunteers. Br J of Anaesth 1997;78(5):507-14.

9. Scott DB, Lee A, Fagan D, et al. Acute toxicity of ropivacaine compared with that of bupivacaine. Anesth Analg 1989;69(5):563-9.

10. Coté CJ, Cohen IT, Suresh S, et al. A comparison of three doses of commercially prepared oral midazolam syrup in children. Anesth Analg 2002;94(1):37-43.

11. Holliday MA, Segar WE. The maintenance need for water in parenteral fluid therapy. Pediatrics 1957;19(5):82332.

12. McFarlan CS, Anderson BJ, Short TG. The use of propofol infusions in paediatric anaesthesia: a practical guide. Paediatr Anaesth 1999;9(3):209-16.

13. Mani V, Morton NS. Overview of total intravenous anesthesia in children. Paediatr Anesth 2010;20(3):21122.

14. Locatelli B, Ingelmo $P$, Sonzogni $V$, et al. Randomized, double-blind, phase III, controlled trial comparing levobupivacaine $0.25 \%$, ropivacaine $0.25 \%$ and bupivacaine $0.25 \%$ by the caudal route in children. $\mathrm{Br} \mathrm{J}$ Anaesth 2005;94(3):366-71.

15. Kaya Z, Süren M, Arici S, et al. Prospective, randomized, double-blinded comparison of the effects of caudally administered levobupivacaine $0.25 \%$ and bupivacaine $0.25 \%$ on pain and motor block in children undergoing circumcision surgery. Eur Rev Med Pharmacol Sci 2012;16(14):2014-20.

16. Ingelmo PM, Locatelli BG, Sonzogni $\mathrm{V}$, et al. Caudal $0.2 \%$ ropivacaine is less effective during surgery than $0.2 \%$ levobupivacaine and $0.2 \%$ bupivacaine: a double-blind, randomized, controlled trial. Pediatric Anesthesia 2006;16(9):955-61.

17. Astuto M, Disma N, Arena C. Levobupivacaine $0.25 \%$ compared with ropivacaine $0.25 \%$ by the caudal route in children. Eur J Anaesthesiol 2003;20(10):826-30. 
18. Ioivani G, DeNegri P, Conio A, et al. Comparison of racemic bupivacaine, ropivacaine, and levo-bupivacaine for pediatric caudal anesthesia: effects on postoperative analgesia and motor block. Reg Anesth Pain Med 2002:27(2):157-61.

19. Ivani G, De Negri $P$, Lonnqvist $P A$, et al. Caudal anesthesia for minor pediatric surgery: a prospective randomized comparison of ropivacaine $0.2 \%$ vs levobupivacaine 0.2\%. Pediatric Anesth 2005;15(6):491-4.

20. Ray M, Mondal SK, Biswas A. Caudal analgesia in paediatric patients: comparison between bupivacaine and ropivacaine. Indian J Anaesth 2003;47(4):275-8.
21. Dobereiner EF, Cox RG, Ewen A, et al. Evidence-based clinical update: which local anesthetic drug for pediatric caudal block provides optimal efficacy with the fewest side effects. Can J Anaesth 2010;57(12):1102-10.

22. Breschan C, Jost R, Krumpholz R, et al. A prospective study comparing the analgesic efficacy of levobupivacaine, ropivacaine and bupivacaine in pediatric patients undergoing caudal blockade. Pediatr Anesth 2005;15(4):301-6.

23. Frawley GP, Downie S, Huang GH. Levobupivacaine caudal anesthesia in children: a randomized double-blind comparison with bupivacaine. Paediatr Anaesth 2006;16(7):754-60. 